\title{
Lost iron during serpentinization and implications for the origin of life
}

\author{
CHEN CHEN ${ }^{12}$, WEI-DONG SUN ${ }^{234}$ AND XING DING ${ }^{5}$ \\ ${ }^{1}$ CAS Key Laboratory of Mineralogy and Metallogeny, \\ Guangzhou Institute of Geochemistry, Chinese Academy \\ of Sciences, Guangzhou 510640, China \\ (chencchina@gmail.com ) \\ ${ }^{2}$ University of Chinese Academy of Sciences, Beijing \\ 100049, China \\ ${ }^{3}$ Center of Deep Sea Research, Institute of Oceanology, \\ Chinese Academy of Sciences, Qingdao 266071, China \\ (weidongsun@qdio.ac.cn ) \\ ${ }^{4}$ Laboratory for Marine Mineral Resources, Qingdao \\ National Laboratory for Marine Science and Technology, \\ Qingdao 266237, China \\ ${ }^{5}$ State Key Laboratory of Isotope Geochemistry, Guangzhou \\ Institute of Geochemistry, Chinese Academy of Sciences, \\ Guangzhou 510640, China (xding@gig.ac.cn )
}

Earth's lithospheric mantle is characterized by hydrated peridotite with the existence of sea water on Earth, generating ubiquitous serpentinites beneath oceanic crust and on the bottom of forearc mantle wedge. The associated release of molecular hydrogen $\left(\mathrm{H}_{2}\right)$ and methane $\left(\mathrm{CH}_{4}\right)$ could provide the metabolic energy and raw materials to support microbial communities, potentially contributing to the origin and evolution of early life on Earth[1-2]. However, availability of nutrients, such as iron, during serpentinization could be the limitation for development of life. Furthermore, whether iron can be mobilized during serpentinization is still controversial [3]. By compiling the geochemical composition of global serpentinites, including both forearc and abyssal serpentinites, we here show that both kinds of serpentinites show higher $\mathrm{Mg} \#[\mathrm{Mg} /(\mathrm{Mg}+\mathrm{Fe})]$ than their peridotite protolith, suggesting considerable iron lost during the transformation of peridotites to serpentinites. We then turn to iron isotope systematics of a set of mantle wedge serpentinites from eastern China, which exhibit heterogeneity of iron-rich minerals within various length-scales. A remarkable positive correlation between $\delta^{56} \mathrm{Fe}$ and $\mathrm{Mg} \#$ is observed, consistent with iron lost in the form of isotopically light ferrous. Thus, the lost iron during peridotite hydration potentially supplies iron nutrients for early Earth biological community.

[1] Kelley D S, et al. A serpentinite-hosted ecosystem: the Lost City hydrothermal field. Science, 2005, 307(5714): 1428-1434. [2] Ménez, B, et al. Life in the hydrated suboceanic mantle. Nature Geoscience, 2012, 5(2), 133-137. [3] Scott, S. R, et al. On the hydration of olivine in ultramafic rocks: implications from $\mathrm{Fe}$ isotopes in serpentinites. Geochimica et Cosmochimica Acta, 2017, 215: 105-121. 